\title{
Bias, Misinformation and the Paradox of Neutrality
}

\section{Peter M. Bednar and Christine Welch Lund University, Sweden; University of Portsmouth, UK}

\author{
peter.bednar@ics.lu.se; christine.welch@port.ac.uk
}

\begin{abstract}
What is normally described as bias? A possible definition comprises attempts to distort or mislead to achieve a certain perspective, i.e. subjective descriptions intended to mislead. If designers were able to exclude bias from informing systems, then this would maximize their effectiveness. This implicit conjecture appears to underpin much of the research in our field. However, in our efforts to support the evolution and design of informing systems, the way we think, communicate and conceptualize our efforts clearly influences our comprehension and consequently our agenda for design. Objectivity (an attempt to be neutral or transparent) is usually regarded as exclusion of bias. However, claims for objectivity do not, by definition, include efforts to inquire into and reflect over subjective values. Attempts to externalize the mindset of the subject do not arise as part of the description. When claims to objectivity are made, this rarely includes any effort to make subjective bias transparent. Instead, objectivity claims may be regarded as a denial of bias. We suggest that bias can be introduced into overt attempts to admit subjectivity. For example, where people are asked to give subjective opinion according to an artificially enforced scale of truthfalsity (bi-valued logic), they may find themselves coerced into statements of opinion that do not truly reflect the views they might have wished to express. People do not naturally respond to their environment with opinions limited to restricted scales; rather, they tend to use multi-valued, or para-consistent logic. This paper examines the impact of bias within attempts to establish communicative practice in human activity systems (informing systems).
\end{abstract}

Keywords: bias, misinformation, phenomenology, multi-valued logic, informing systems, analysis.

\section{Introduction}

For those concerned with the development and use of informing systems, it is important to consider human processes of communicating and sense-making. These processes underpin any attempt a person may make to inform herself or to help others to inform themselves. At the heart of an informing system is an assumption that it is possible to generate messages that can become meaningful to others. This is reflected in

Material published as part of this publication, either on-line or in print, is copyrighted by the Informing Science Institute. Permission to make digital or paper copy of part or all of these works for personal or classroom use is granted without fee provided that the copies are not made or distributed for profit or commercial advantage AND that copies 1) bear this notice in full and 2) give the full citation on the first page. It is permissible to abstract these works so long as credit is given. To copy in all other cases or to republish or to post on a server or to redistribute to lists requires specific permission and payment of a fee. Contact Publisher@InformingScience.org to request redistribution permission. the words of Eli Cohen, who suggests that:

'the term Informing Science applies to disparate fields that share the common goal of providing a client with information in a form, format and schedule that maximizes its effectiveness' (1999, p.217). 
Knox (2007) has drawn attention to differing perspectives affecting use of the term 'information'. This term is sometimes used to denote a business resource, i.e. a commodity which can be stored and exchanged. Here it is viewed as no more than structured data. However, other perspectives reflect the intimate involvement of human individuals in creating, interpreting and attempting to communicate meaning. Here, a focus may be placed upon processes of informing, rather than the notional products of these processes. In the Oxford English Dictionary (OED) (1989) information has been defined as:

'Knowledge communicated concerning some particular fact, subject, or event; that of which one is apprised or told; intelligence, news esp. contrasted with data.'

Such a definition is not particularly helpful since it requires the reader to make reference to other, associated or contrasted terms. For the purposes of this paper, we prefer to concentrate on the verbs that it includes: communicated; apprised; told. All of these are essential aspects of 'informing'. For many people, becoming informed about a subject carries with it an imputation that messages can be received (from some external source) for which veracity can be assured. This leads us to consider the extent to which we can assess 'truth' of any particular message. In this context, the OED gives us some further definitions:

'Misinformation - erroneous or incorrect information'; 'Propaganda - systematic propagation of information or ideas by an interested, esp. in a tendentious way in order to encourage or instil a particular attitude or response'; 'Disinformation - the dissemination of deliberately false information ... with the intention of influencing the policies or opinions of those who receive it'.

Each of these terms implies presence of bias. This has been defined as personal inclination or preference to favour a particular viewpoint with failure to fully inform a direct consequence (Cohen, 2005). We do not wish, in this paper, to focus on introduction of bias, or falsehood, which is deliberately undertaken for particular purposes. We confine our attention to situations in which those who undertake inquiry, or generate messages, may intend their efforts to be genuine or neutral and yet nevertheless find themselves entrapped in processes of misinforming. Maqsood, Finegan, and Walker (2004) point to the limitations of the human mind in dealing with tacit knowledge. Heuristic judgments undertaken in the process of formulating messages, and imperfections in memory over time, can lead to unconscious bias. It is important to note that a phenomenon of bias is not associated only with the senders of messages; misinformation can equally be a result of bias in the interpretation of a message by its receiver, or indeed by both parties.

\section{Bias}

In this section, we look at the phenomenon of bias in relation to some of the concepts through which its origins can be examined. We look at alternative models of 'communication' as a process of transmitting messages, noting a difference in focus. Form, and content are emphasized in one model, whereas the impact of the message on a recipient is emphasized in another. Issues of human sense-making and interpretation of messages are then discussed, particularly highlighting use of language. Here, denotative (naming) functions are distinguished from connotative (associating) functions of language.

In common use, the term bias often has negative connotations - i.e. bias is equated with prejudice, and prejudice is seen as an evil to be avoided in favour of 'objectivity'. However, like the parallel concepts of sense and nonsense, distinctions between bias and objectivity relate to subjective 'judgement' - bias from whose point of view?

In a process model of communication, (see e.g. Shannon \& Weaver, 1949) there are interpreters/producers of messages who utilize a particular medium - a technical or physical means for transformation of a message to a signal, which can be transferred via a channel (see Figure 1.). 
This channel is the physical means with which the signal is transferred. Messages are encoded and decoded.

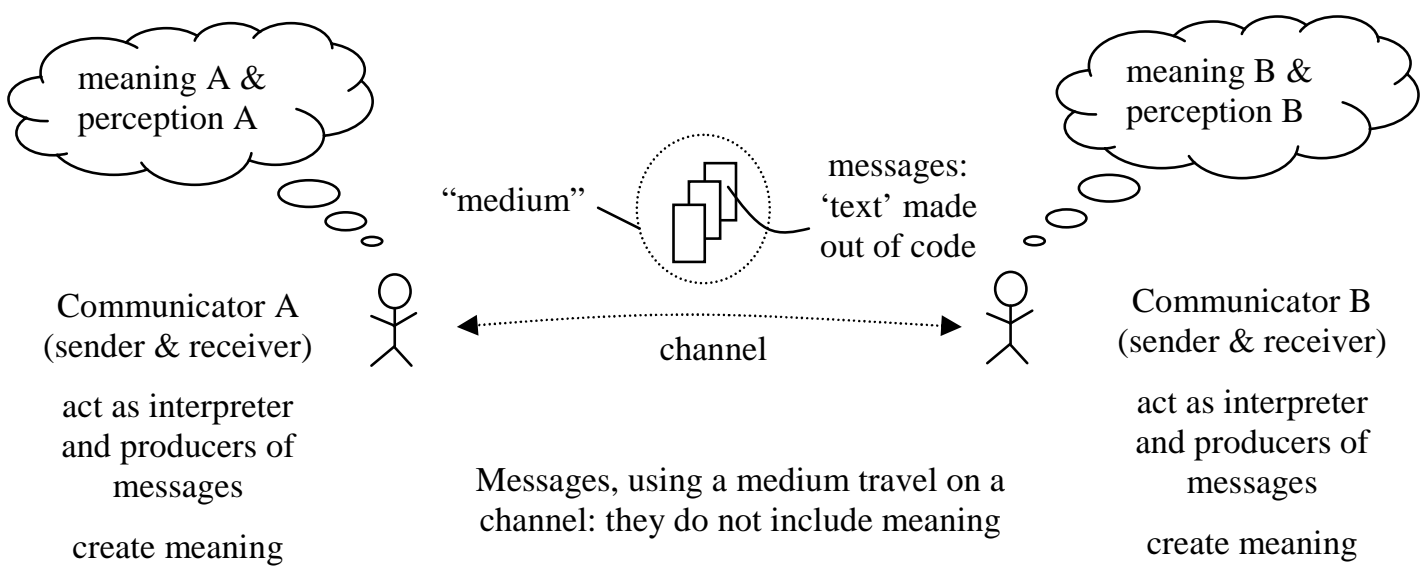

Figure 1: Typical process model of communication

The physical and technological properties of a medium define the selection of codes which can be used ('sent' or 'received'). Choice of medium and code is dependent on the use, ability, and availability of the five human senses (see Figure 2).

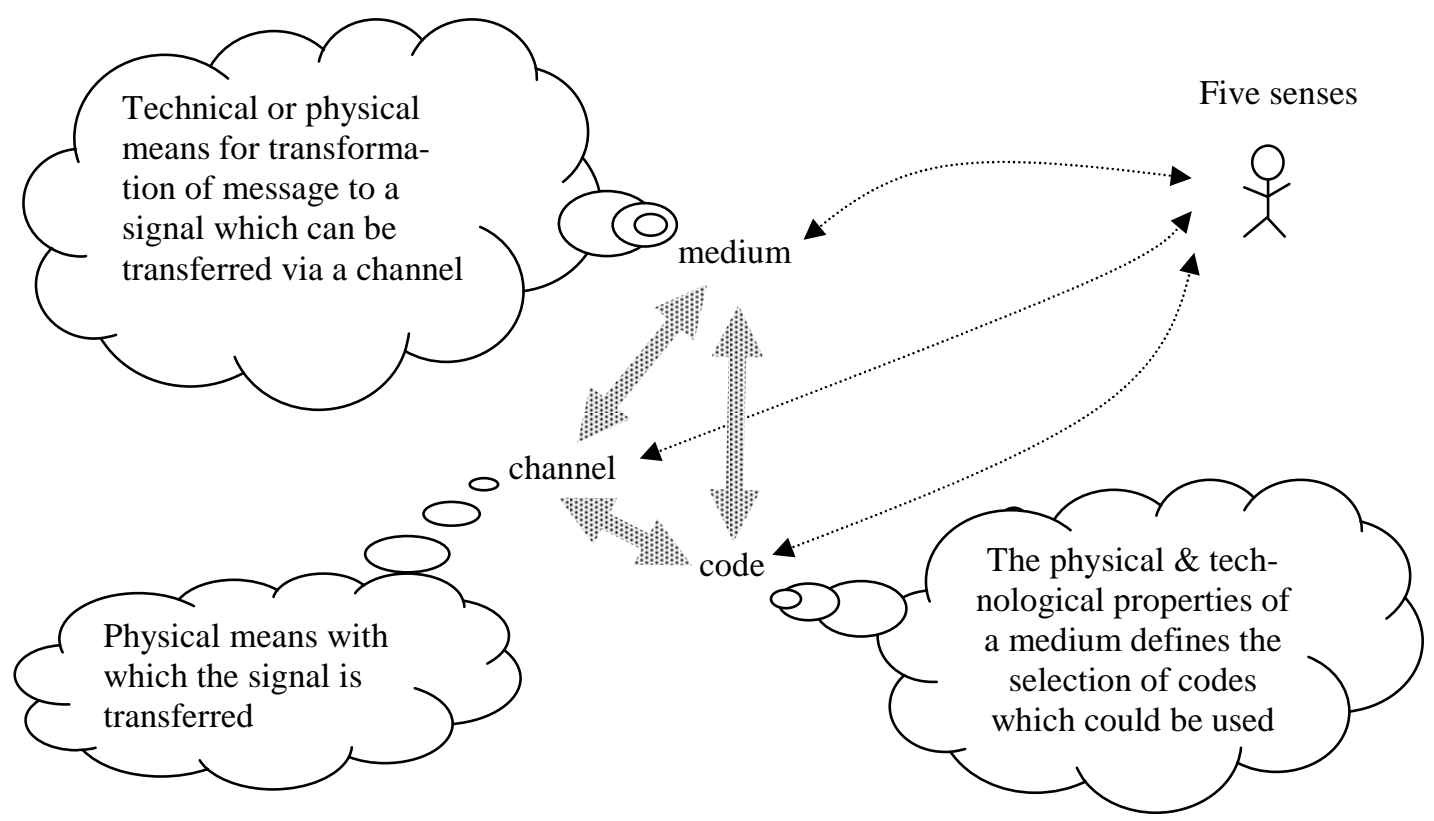

Figure 2: Aspects of a process model of communication 
Both producers (sender and receiver) constantly check their interpretation of the message against references - e.g. previous experiences of the way in which such messages could be interpreted. In a semiotic model of communication, socio cultural and other influences on such references are highlighted (e.g. Fiske, 1982; Saussure, 1974). Typically, in a process model, we might focus on bias on the part of the sender, e.g. when she wishes to convince the receiver of her opinion about something, bias might be introduced into the form and content of the message. However, it is not only the sender who is a producer. When decoding a message, a receiver interprets and creates meaning by relating to reference(s). Bias is present therefore through the actions of both parties. However, it is unlikely to be the same bias.

In some process models, (e.g. Lasswell, 1948) meaning is regarded as irrelevant for communication practice and theory (see Figure 3). Effect is seen as a more relevant focus for attention - i.e. communication is about creating effects (actions) not understandings. Who says what, through which channel, to whom, with what effect? Communication is about interest and control, not about meaning.

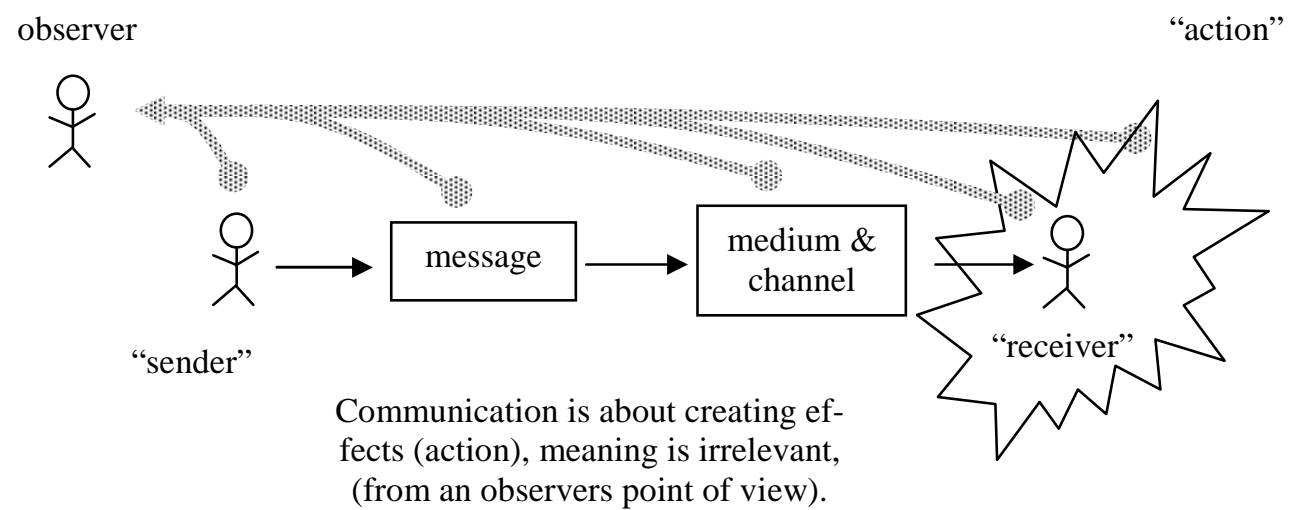

Figure 3: Lasswells' model of communication

Richards (1968, p.157) calls the process-oriented model a 'vulgar packaging theory of communication'. In his view, the Shannon and Weaver model is suggesting that there can be a core message that exists independently of human interpretation. This message is then encoded (packaged) for further transfer. The recipient de-codes (unpacks) the message and exposes the core content and form. According to Richards, the misconception here lies in a belief that a message can exist before it has been articulated (or coded). Articulation is essentially a creative process. At first, there is only a wish to articulate, not a pre-existing content that needs only to be coded. In other words, there is no content before the message is given form, and efforts to find differences between form and content would become highly questionable, to the point of being futile. Form and content are always one 'package' - one cannot subsist independently of the other. Content is not simply presented by form. There is a relationship between content and form that is dynamic and 'co-acting'. Each combination of content and form is unique, in the sense that any change of form will also change the content. Recognition of a change of form by a human reader of the message must by definition conjure different associations from that person's past history - thus changing her interpretation of the message. Each element, and the relationship between them, are essential characteristics of the message, which influence and change it. We can reflect that Gregory Bateson's view of information as 'a difference that makes a difference' suggests similar reasoning (Bateson, 1972). 
In the field of semiotics, researchers (e.g. Fiske, 1982) tend to prefer the term 'reader' to that of 'receiver' (and tend not to focus specific attention on 'senders'). In semiotics, sense-making and interpreting (i.e. 'reading') are the focus of interest. This forms a link between semiotics and linguistics. Consider the relationship that subsists between a territory (world) and a 'map' that supposedly represents it. A map may appear initially to be a simple metaphor for the territory, but at the same time this relationship is complex. We recognize that the territory is not the map and vice versa. However, there are quite a few different categories of 'maps'. Examples include street plans; geological maps; those depicting water levels and flows; navigation charts; maps showing sources of raw materials; bio-diversity or climate zones; plans showing phone land lines etc - all these specialist purposes can be covered by specialist 'maps', each of which may take a different form, with different signs and signifiers.

Successful communication (from the perspective of the recipient) cannot necessarily be equated with an outcome of a convinced audience or an effective intended result or action. Consider the following statements (see Table 1) as responses from a reader of a message; each might be regarded as a 'success' in communication. However, only one of them can be seen to be successful in terms of resultant effect (including non-action as an effect). A person might say "I think I understand you", indicating that she is uncertain. However, she might equally say "I understand you" believing that she is certain, unaware that she has misunderstood. Likewise, a person might be convinced that she does not understand when in fact she does, e.g. "Surely, it cannot be that simple." Success in communication could instead be discussed in relation to both intended and unintended consequences; to both recognized / observed consequences and those which are unrecognized / unobserved.

Table 1: Variations of successful communication

- I understand what you mean - but I do not agree with you;

- I agree that you are right - but I do not care, and will not therefore take the action you suggest;

- I agree that you are right - but I cannot take the action you suggest (... because I lack the necessary courage; I lack the physical capability; I lack the necessary will power; I lack the economic means, etc) to act on my agreement with you;

- I understand and agree - I will take it the action you suggest when I have the time (... privately I am prevaricating because I am in denial of my real disagreement with the suggested action, or because my agreement is weak and I see it as a low priority);

- Yes I agree - and will immediately act accordingly. (Claim)

- Yes I agree - and will immediately act accordingly. (Observed effect)

Maturana (in Maturana \& Varela, 1980) considers this in his discussion of the role of language in human interaction. He suggests that linguistic behavior is orienting behavior. Consensual orienting interactions are only possible where the (cognitive) domains of interaction of each organism are to some degree comparable, so that they are able to develop some system of communicative descriptions.

"So long as language is considered to be denotative it will be necessary to look at it as a means for the transmission of information, as if something were transmitted from organism to organism, in a manner such that the domain of uncertainties of the 'receiver' should be reduced according to the specifications of the 'sender'. However, when it is recognized that language is connotative and not denotative, and that its function is to orient the orientee within his cognitive domain 
without regard for the cognitive domain of the orienter, it becomes apparent that there is no transmission of information through language. It behooves the orientee, as a result of an independent internal operation upon his own state, to choose where to orient his cognitive domain; the choice is caused by the 'message', but the orientation thus produced is independent of what the 'message' represents for the orienter." (Maturana, in Maturana and Varela, 1980, p.32).

Nissen (2002) also points to the distinction between connotative and denotative usage of language. He suggests that human communication, as described by Maturana (Maturana and Varela 1980), does not presuppose a conduit metaphor (as in a simplistic understanding of the Shannon and Weaver model), but is consistent with perception of people as creative beings. The denotative function of information, in the context of information systems development and use, is generally taken for granted. Nissen uses the phrase 'Information System' to refer to information processing and management processes comprising both social and technical elements. He underlines the fact that the denotative function of language presupposes much prior interaction and mutual learning among orienters/orientees. This often seems 'grossly underestimated when software systems are incorporated into information systems' (Maturana, in Maturana and Varela, 1980 p.81).

Thus, while many are very aware of the denotative features of language, the connotative features are often ignored. It may be beneficial that denotative features should dominate in some specialist contexts, e.g. particular technological contexts such as that contemplated by Shannon and Weaver when they developed their model of communication in a specifically engineering environment. Here, a specific 'jargon' can be useful within the immediate context among those attempting to orient one another in very specific ways. However, in informing systems generally, the denotative meanings should not be taken as self-evident. Neither denotative nor connotative features of language should be focused upon in isolation from one another. This point is taken up by Apel (1980) in the context of theories and methods of inquiry; by Bateson (1972) in a context of different types of systems thinking; by Radnitzky (1973), drawing upon work by Habermas, in a context of communicative action; and by Nissen (2002), in a context of traditions of inquiry in software development.

In this section, we have focussed on communicating, use of language and the processes by which human individuals interpret messages in their efforts to communicate. These were highlighted in order to elucidate some possible origins of 'bias'. We now move on to consider some philosophical concepts that influence our perspectives on human communication and interpretation of meaning.

\section{Philosophical Foundations}

In this section, we consider how different philosophical perspectives treat the issue of communication among human beings. In particular, we contrast the Logical Empiricist school of thought with that of Hermeneutic Dialectics. These are discussed in order to highlight the problematic nature of communication and a need to avoid oversimplification by treating processes of sensemaking and interpretation as if they were merely issues of transmission of the right signals.

The term 'information' is used in a number of ways by different researchers, reflecting different perspectives (see Callaos \& Callaos, 2002). For example, Langefors (1966), in his Infological equation (see Figure 4), specifically allies the term information with meaning, brought about through interpretation. Shannon and Weaver, however, in their 1949 model of communication, specifically state that 'information must not be confused with meaning' (p.99). However, these authors specifically draw their readers' attention to this as a variant on common usage, by pointing out that

'The semantic aspects of communication are irrelevant to the engineering problem' (p.3). 
Richards (1968) points to a dangerous confusion that can lie in wait for a naïve researcher who attempts to apply Shannon and Weaver's model, or Laswell's (1948) formula, uncritically in a context of human communication. The term information, when used by the authors of this paper, refers to meaning, drawing upon data interpreted (created) by human sense-making processes, including application of bias by its producer.

\section{$I=\mathbf{i}(\mathbf{D}, \mathbf{S}, \mathbf{t})$}

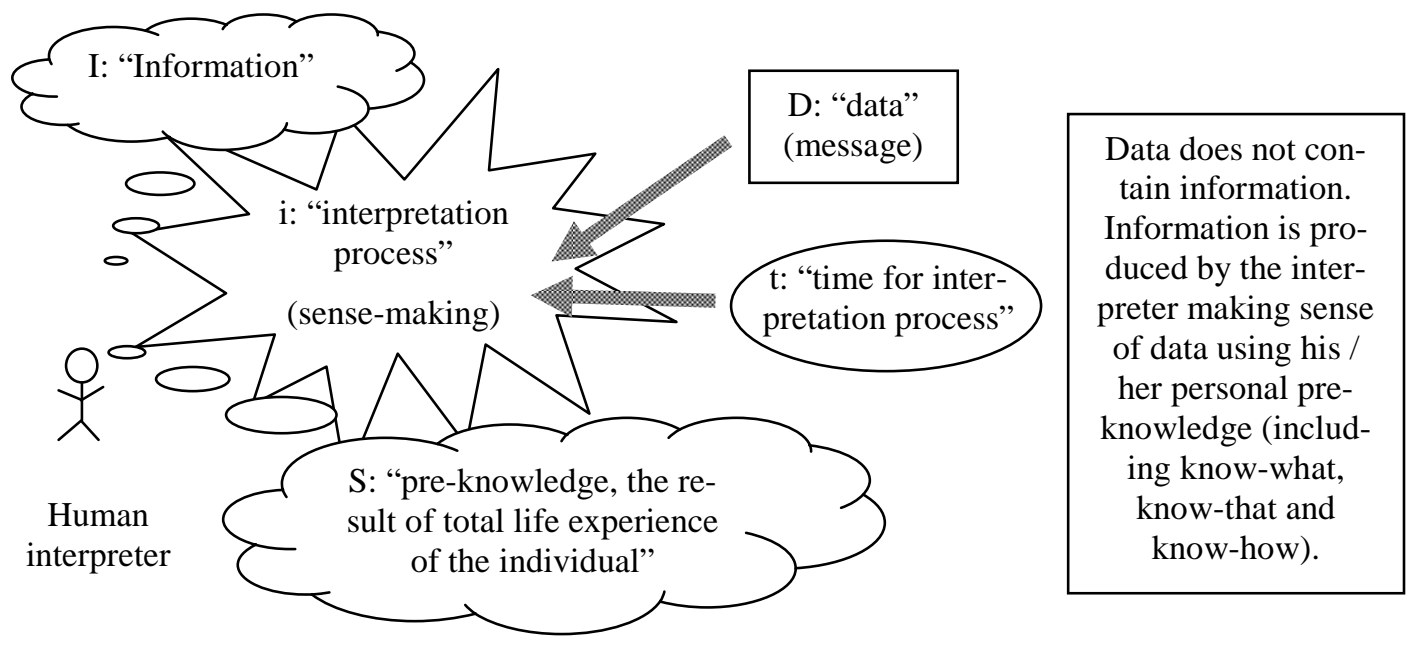

Figure 4: The Infological Equation

A simple transmission or conduit model of communication is therefore rejected, since the relation between form and content, and the interpretation through human sense-making (application of bias) cannot be reduced to technological applications only (see also Nissen, Bednar, \& Welch, 2007). Thus, ideal 'informing' efforts are more than just attempts at information provision, because two-way communication processes are essentially involved (two-way informing). This requires us to consider an expanded model, and move from information exchange to communication and relation-inclusive interpretation. This argument is strengthened by reference to works of e.g. Bateson (1972), and Hay (2007). In this way, our intention is to incorporate a recognition of the double hermeneutic involved when sentient human beings interact. It could be helpful also to consider this process as communi-forming, inter-forming, conforming ... etc. In particular, we wish to contrast perspectives based in logical empiricism (LE) with those based in hermeneutic dialectics (HD). These perspectives may be seen as complementary (rather than antagonistic), but inquiries conducted within each are likely to have different objectives and result in differing types of discourse.

Drawing on Nissen (2002) and Radnitzky (1973), the authors have compiled Table 2, which summarises the distinctive features of each of these paradigms as they relate to a phenomenon of bias. 
Table 2: Logical Empiricist and Hermeneutic Dialectic Views of Bias

\begin{tabular}{|c|c|c|}
\hline Feature & Logical Empiricism & Hermeneutic Dialectics \\
\hline $\begin{array}{l}\text { View of } \\
\text { 'reality' }\end{array}$ & $\begin{array}{l}\text { One observer independent reality; } \\
\text { Reality is 'out there' to be discovered; } \\
\text { Bias can and should be avoided as far } \\
\text { as possible in order to get closest to } \\
\text { this reality. }\end{array}$ & $\begin{array}{l}\text { Many coexistent 'realities' dependent on } \\
\text { observers; } \\
\text { Understandings of 'realities' created } \\
\text { through sense-making; } \\
\text { Bias is a necessary part of individual } \\
\text { sense-making processes - what enables } \\
\text { people to make sense of their world. }\end{array}$ \\
\hline $\begin{array}{l}\text { Theory of } \\
\text { truth }\end{array}$ & $\begin{array}{l}\text { Correspondence theories predominate; } \\
\text { Information can exist independently of } \\
\text { human beings. }\end{array}$ & $\begin{array}{l}\text { Coherence theories predominate; } \\
\text { Information is created by individual hu- } \\
\text { man beings and cannot exist without } \\
\text { them. }\end{array}$ \\
\hline $\begin{array}{l}\text { Historical } \\
\text { context of } \\
\text { data col- } \\
\text { lected }\end{array}$ & $\begin{array}{l}\text { Irrelevant because information is in- } \\
\text { dependent of any context. The object } \\
\text { of research is assumed to lead to a giv- } \\
\text { en set of variables; } \\
\text { Boundary of context is taken as given. }\end{array}$ & $\begin{array}{l}\text { Relevant because selection of variables is } \\
\text { dependent upon the choices made by in- } \\
\text { dividuals who collect the data; } \\
\text { Boundary setting is a political process and } \\
\text { questions to be asked are a matter of in- } \\
\text { dividual choice. }\end{array}$ \\
\hline $\begin{array}{l}\text { Causal } \\
\text { connec- } \\
\text { tions }\end{array}$ & $\begin{array}{l}\text { Linear chains or trees; } \\
\text { Efforts are made to define the parame- } \\
\text { ters of a problem requiring rigorous } \\
\text { inquiry; } \\
\text { The domain of the problem space is } \\
\text { taken as given; } \\
\text { Focus is on rigor in inquiry. }\end{array}$ & $\begin{array}{l}\text { Mutual, interlocked influences; } \\
\text { Efforts are made to consider what the } \\
\text { relevant problem space is, and how this is } \\
\text { chosen. } \\
\text { The domain of the problem space is se- } \\
\text { lected by a human actor; } \\
\text { Focus is on relevance in inquiry. }\end{array}$ \\
\hline $\begin{array}{l}\text { Values } \\
\text { guiding } \\
\text { research }\end{array}$ & $\begin{array}{l}\text { Only those which are science- } \\
\text { immanent; } \\
\text { Objectivity, absoluteness and particu- } \\
\text { larity. }\end{array}$ & $\begin{array}{l}\text { Both science-immanent and external val- } \\
\text { ues; } \\
\text { Subjectivity, plurality and relativity. }\end{array}$ \\
\hline $\begin{array}{l}\text { Separabil- } \\
\text { ity of the- } \\
\text { ory from } \\
\text { practice }\end{array}$ & $\begin{array}{l}\text { Strictly separable; } \\
\text { Objectivity follows from this premise. } \\
\text { Subjective elements are excluded from } \\
\text { the process of inquiry. }\end{array}$ & $\begin{array}{l}\text { Theory and practice dialectically related; } \\
\text { Subjectivity and relativity follow from } \\
\text { this premise; } \\
\text { They are inseparable and subjectivity is } \\
\text { inherent in the process of inquiry. }\end{array}$ \\
\hline $\begin{array}{l}\text { Research } \\
\text { interest }\end{array}$ & $\begin{array}{l}\text { Technical research interests, poten- } \\
\text { tially emancipatory; } \\
\text { Desire to create a solution based on } \\
\text { observation of objective 'facts'. }\end{array}$ & $\begin{array}{l}\text { Mainly hermeneutic and emancipatory } \\
\text { interests, can provide social techniques; } \\
\text { Desire to create a resolution based on in- } \\
\text { terpretation of interaction. }\end{array}$ \\
\hline $\begin{array}{l}\text { Main lan- } \\
\text { guage fea- } \\
\text { tures }\end{array}$ & $\begin{array}{l}\text { Extensional and denotational; } \\
\text { Messages, containing meaning (and } \\
\text { knowledge) can be transmitted from a } \\
\text { sender to a receiver. }\end{array}$ & $\begin{array}{l}\text { Intentional and connotational; } \\
\text { Messages are exchanged between an ori- } \\
\text { enter and an orientee; meaning (and } \\
\text { knowledge) is not contained in messages } \\
\text { but is created by participants in an orien- } \\
\text { tation process. }\end{array}$ \\
\hline
\end{tabular}


We do not discuss scientific proofs or analysis of empirical evidence about communication but rather seek to highlight some of the issues and problems experienced in individuals' efforts to make sense of the world and to communicate one with another - what Heidegger (1962) might have termed 'Befindlichkeit'. Our perspective is also informed by an appreciation of phenomenology as an underpinning philosophy of inquiry. Alfred Schutz reminds us that:

"all empirical sciences refer to the world as pre-given, but they and their instruments are themselves elements of this world. Only a philosophical doubt cast upon the implicit pre-suppositions of all our habitual thinking... can guarantee the 'exactitude' not only of such a philosophical attempt itself but of all the sciences dealing directly or indirectly with our experiences of the world..." (Schutz as cited in Wagner, 1970, p 54).

Schutz goes on to comment on attempts to attach to phenomenology labels, such as idealism, realism or empiricism. These, he regards as inadequate in application since by its nature phenomenology puts them all in question. Phenomenologists seek to include in their inquiry a sensemaking space that comes before the point where many other philosophers begin.

Communication is a key concept here. Habermas (1985) describes difficulty among human beings in achieving communication; there is a need for strategies, such as 'languaging' to enable people to explore one another's sense-making processes (see Wittgenstein, 1963). When elaborating upon 'meaningfulness' some authorities (e.g. Schutz) question how it is possible for any mutual understanding or communication between people to take place, and how a person can act purposively in order to achieve actions that are meaningful.

This section has highlighted the problematic nature of human communication, by comparing perspectives from two contrasting schools of thought. We now go on to look at the phenomenon of misinformation, using the particular contexts of IS-related disciplines to provide illustrations.

\section{Misinformation in Informing Systems}

In this section, we explore some examples of ways in which 'misinforming' can arise. We note, particularly, that an intention to mislead on the part of the originator of messages is not necessarily required. Even if we choose to accept that all parties act in good faith, the impact of misinforming can be the same.

In the Information Systems and IT area, there is a long history of developing methods and techniques to support informing practices in complex problem-solving and development projects (e.g. Checkland, 1999; Mumford, 2003; Nissen, 1989). When information technologies began to be developed for organizational purposes, it was soon discovered that there was a gap in communication between technologically-oriented and business-oriented staff. This is recognized not only in the academic world but also in industry and is discussed in an IBM white paper on IT service management (Salvage \& Dhanda, 2007). Furthermore, although systems development can be conceived as an integrated process, in practice attempts to standardize the steps and techniques involved have led to less, rather than more, comprehension among the various communities of practice seeking to establish the meanings of these aspects. For example, within an overall context of 'Application Lifecycle Management' different providers have generated a range of different interpretations of what is supposed to be a standardized process (Baer, 2007a). It could be argued therefore that the informing science transdiscipline, applied to information systems, is an emerging result of developers and researchers recognizing misinforming communication breakdowns (e.g. Nissen, 2002). In the discipline of information systems, this can be observed in the many efforts to create standardized languages, methods and techniques intended to support complex communication and interaction between different stakeholders in a systems development project. However, because these efforts have not proved to be entirely successful in achieving 
their aims, they continue to be of major interest for this community of practice. As Baer (2007b) comments:

'the nice thing about standards is that there are so many of them to choose from ... the more standards, the less standardisation.'

The phenomenon of misinformation can be recognized in many aspect of the IS/IT field. The following examples provide anecdotal evidence to illustrate the impact of this.

A Canadian man who had a $\$ 10$ wireless contract that included "unlimited mobile browser plan" was charged with $\$ 85,000$ "because the company was charging him on a per-kilobyte basis" (Haines, 2007). The man who had used his mobile phone as a modem for his PC had not realized that his "unlimited browser plan" did not include unlimited download in the subscription. It could be argued that the man should have known this, especially since when installing necessary software on his computer a warning message was displayed stating that 'additional data charges may be incurred'. On the other hand, the source of potential misunderstanding is clear - that those particular customers having a contract described as including "unlimited mobile browser plan" are not necessarily to be taken as the intended audience for the warning message. This confusion is exacerbated when considering that there are many different wireless contracts available for each customer to choose among. We reflect that it is irrelevant whether this was deliberate attempt to mislead on the part of the service provider - the scope for downloading data to a mobile phone tends to be self-limiting in comparison to other technologies such as a PC. The possibility exists that the company never considered a context of use of a mobile phone as a modem when drawing up the agreement, but the impact on the user is the same.

Recently, Microsoft proudly presented in a press release that they had 'delivered a holiday surprise' unveiling a public beta of a piece of software technology (Vance, 2007). The release was worded as if this release was ahead of schedule. The description went on to include a reference to the company's expectation of being ready in the first quarter of 2008. This was intrinsically flattering in a world where delays are commonplace. While the release date presented was accurate, it was not the original release date. Microsoft had initially presented a plan to ship the software in the first half of 2007. The release was then delayed to the second half of 2007 and then again to the first half of 2008. This latest deadline was the one they eventually managed to beat, ahead of schedule. A cynical observer may conclude that the Press Release was intentionally made in order to mislead the audience into thinking this achievement more attractive than it was. However, because it is possible that this selective 'half-truth' was put forward in good faith, it is irrelevant in our discussion of bias whether this selectivity was purposeful or not.

Do modeling languages improve communication? In a discussion about modelling and designing software solutions, it is recognized that modelling languages (techniques, etc.) can be used for different purposes and this then influences the result of their use. Although the use is within a particular community of practice, and the modelling languages are standardised, this does not guarantee success in efforts for communication between different stakeholders. This is mainly because it is recognised that the purpose for using the modelling language also influences the results of its usage (see for example Rosenberg \& Stephens, 2007). The problem described focuses on the difference between using modelling languages to design a solution from scratch and then use the design to develop and implement code, or to analyse code and reverse engineer a model out of the code. The intention in using the modelling language is to try to make a clear picture of the software design. Stephens comments on the result of the second option as follows:

'... muddy water poured into a crystal flute is still muddy water. Now you've got the same dysfunctional mudball in two places - the code and the UML model' (Stephens, 2007a). 
The conclusion is made that the modelling language cannot in itself create the expected clarity and meaning. This is encapsulated by Stephens (2007b), when he comments as follows.

'Imagine if everyone on your team was talking a different language. Let's say you're speaking German, your team mate is speaking French, and someone else is speaking Swahili.

Every time someone speaks, people glean whatever slivers of meaning they can, and then nod as if they've understood perfectly. They then walk away with a completely wrong interpretation of what the speaker was really trying to say.

In virtually all IT projects, the problem of miscommunication is rampant, but it's rarely noticed because everybody thinks they're speaking the same language. They're not. One person says 'book review' and some people interpret this as meaning 'editorial review' (a review written by an editorial team), whereas others might interpret it as meaning 'customer review' (a review written by a customer and posted to the site).

The results can be - and often are - catastrophic, as the system gets developed with everyone interpreting the requirements and the design differently.'

These examples show concerns within the community of practice about the proliferation of perceived communication breakdowns. This is further compounded in academic discourse on methods/approaches, with statements such as 'closing the gap' (Sommerville, 2007), in a context of software engineering); 'bridging the gap' (Avison \& Fitzgerald, 2002), in a context of method) and 'navigating the gap' (Stowell \& West, 1994), in a context of client-led design).

In this section, we have shown how misinforming can take place using examples from the IS field. We have seen that intention to mislead is not a necessary condition for misinforming to take place and that, even within communities of practice with common interests, misinforming may be rife. We now turn our attention to two particular cases where human activity, intended to inform, can actually result in misinforming. The first of these arises through misguided attempts to achieve 'objectivity'. We explore, through discussion of Hermeneutic Dialectics (introduced in the previous section) how such efforts cannot meet with success. The second case arises when those seeking to inform are constrained by artificially imposed criteria based in bi-valued logic (e.g. yes/no; true/false) which tend to filter out richness and complexity of 'meaning'.

\section{Paradox of 'Objectivity'}

This section describes how attempts to achieve objectivity can lead to misinforming. If, in metaphysics, it were possible to identify a number of different and (in some cases) incompatible versions of 'interpretivism', it would be highly questionable to proceed as if there were only one. See, for example, the discussion by Radnitzky (1973) in which he discusses a number of different schools of thought, including different variants of interpretivism. The authors would prefer to avoid making an assumption that there is only one particular variant. For example, we may look at the difference in assumptions between logical empiricism and hermeneutic dialectics. Inquiries based in an LE tradition are likely to give great attention to precision and clarity in expressing a problem situation. Radnitzky (1973) points to a danger within such inquiries that an artificial separation may arise between observations made and the unique perspectives of observer and observed. Adopting such a focus of attention could consequently lead to a loss of critical awareness and entrapment in a confusion between specific and general sable descriptions of experiences. Researchers whose inquiries are based in philosophical practice from an Hermeneutic Dialectics tradition, on the other hand, are likely to make explicit efforts to recognize uncertainty/ambiguity as features of socially constructed perspectives on human activity. Their focus is intended to be on transparency, rather than clarity, emphasizing individual self-awareness. Both traditions could be described as leading to a very different strand of 'interpretivism', one focusing on clarity and 
the other on transparency. The authors also wish to avoid suggestions that any approach, with its underlying philosophy, is directly linked with predetermined sets of methods for investigation. Such a view is also highly questionable. If we consider the work of leading researchers within any paradigm, they may (in principle at least) choose to use any method for investigation. Application of method does not necessarily explain the philosophy underpinning any particular research. However, the justification of method use, the choice of variables, the choice of boundary settings, the arguments related to validity, etc. are dependent upon the particular philosophical interpretation and stand adopted by the particular method user. This is illustrated in work by Werner Ulrich (1994). In efforts to provide help for citizens attempting to communicate with experts, Ulrich develops a method for critical systemic thinking and emphasizes a need for 'boundary critique', i.e. awareness of the impact of drawing boundaries around spheres of interest within problem situations. In a context of information systems, Ciborra (2002) draws on work of Edmund Husserl in order to urge a need for a phenomenological understandings. In doing so, he draws attention to a common '...forgetting of issues such as the subjective origin of science, the foundational role of everyday life in the creation and development of any methodology, and, ultimately, the obliterating of authentic human existence in the management of organizations and technologies' (Ciborra, 2002, p. 15).

For example, where interpretive research refers extensively to work by Heidegger, Gadamer, possibly Husserl and Habermas, it might be alleged to be grounded in idealistic, metaphysical thinking (for an example of this discussion, see Radnitzky, 1973). Perhaps, therefore, efforts should also be made to refer to authors such as Bateson, Apel and Schutz in attempting to apply philosophy in practice (Apel, 1980; Bateson, 1972; Schutz, 1967). Researchers struggle to bring scholarly illumination in touch with everyday experience, as suggested by Randall Whitaker:

"...this literature can be characterized as scholarly, i.e. abstract or theoretical in content. Fine points of philosophy have been examined in relative isolation from consideration of how they might pertain to the workaday world. Regardless of its illumination of 'meaning' or 'reflection' such theoretical work rarely addresses either the 'meaningful use' or 'reflection upon use' at the center of my professional ...work." (Whitaker, 2007).

An idea that meaningful communication has taken place can be based in an 'illusion' that there is some objective reality to which both parties are referring. When elaborating upon 'meaningfulness' Schutz (1967) questions how it is possible for any mutual understanding or communication between people to take place, and how a person can act purposively in order to achieve actions which are meaningful. He reflects that such possibilities can only be approached via 'sedimentation' of pre-interpreted experiences built up through conscious life. Any justifiable methods for interpreting social interrelationship must then be based on careful description of underlying assumptions and their implications. He goes on to suggest that the methods of the social sciences cannot be regarded as adequate to this task.

"These questions cannot be answered by the methods of the social sciences. They require a philosophical analysis. And phenomenology ... has not only opened up an avenue of approach for such an analysis but has in addition started the analysis itself' (Schutz, as cited in Wagner, 1970, p. 56).

This concept of 'sedimentation' of pre-interpeted, lived experience comes about, for Alfred Schutz, through reflection. While conscious life may be described as a continuous flow of experience which moves only forward and is irreversible, the act of paying attention to living experience removes the subject from the flow and marks out one 'experience' from another for description or reflection. In reflection, the individual is essentially stepping out and turning against the 'flow'. Thus, meaningfulness can only be attributed in retrospect. To illuminate this, we can paraphrase Dylan Thomas' well-known poem and consider the idea of reflection on 'an experi- 
ence ago'. As Bohm (1992) points out, 'thought' as a concept always implies a passage of time. We are always in the process of thinking but any 'thought' can only be considered in retrospect, when it no longer exists as experience. It should be noted that Schutz' view has been subject to criticism by some authorities, e.g. Habermas, who suggests that a transcendental view of the 'lifeworld' fails to take into account a possible role for objective challenges to pre-interpretation (Habermas, 1985, p.401). For the purposes of the discussion in the current paper, however, the authors do not see Habermas' position as contradictory. The reason for this is that the 'objective challenge' would be based upon collections of subjective assumptions referring to a 'common' (which is itself a socio-cultural temporality).

In considering Schutz's view, the authors are reminded of the work of Börje Langefors, in the mid-sixties, with the Infological Equation. Reflecting on the nature of information systems, Langefors $(1966 ; 1995)$ suggests that those people who are to interpret data in order to inform themselves must be viewed as part of the system. He demonstrates this using the infological equation $\mathrm{I}=\mathrm{i}(\mathrm{D}, \mathrm{S}, \mathrm{t})$ where " $\mathrm{I}$ " is the information (knowledge) produced by a person from data " $\mathrm{D}$ " in conjunction with pre-knowledge " $S$ ", by an interpretation process " $\mathrm{i}$ ", during time interval " $\mathrm{t}$ " (Langefors, 1995, p.144). Meaning (information or knowledge) is thus created by each individual. Pre-knowledge " $\mathrm{S}$ ", here, is considered to be created through the entire lived experience of the individual concerned (cf Schutz's concept of 'sedimentation').

Like Schutz, Langefors reflects on the apparent impossibility of communicating 'meaning' between people. Simply transmitting data will not lead to communication of a shared understanding, since, by their nature, "i" and "S" cannot be assumed to be common. He observes that communication may be seen to approach success most closely where individuals interpreting the same data belong to a group, definable for example by locality or common professional interest, e.g. standardized accounting data among accountants. He concludes that every act of interpretation does not necessarily invoke the entire "S" attributable to every individual and that some aspects of shared experience may be sufficient to lead to similarities in "i" among group members. In seeking to reconcile this counter-intuitive phenomenon with the logic of the equation, Langefors makes a philosophical distinction in the nature of interpretive processes. Any simple piece of data might be interpreted by different individuals to have a similar 'factual' meaning. However, inferences drawn from such facts would be likely to differ more widely - the 'meaning' of the data for an individual in terms of its associations, and/or possible consequences depending upon her/his unique "S". Communication and intention is context-dependent. Interpretation of context continually changes over time and this influences sense-making and communication efforts (see Wittgenstein (1963), e.g. his later work and his discussion of language games). Constant change of interpretation, and consequently of perceived meaning, (e.g. information) was highlighted by Langefors in the infological equation in 1966 (see Langefors, 1966). This view is supported by Klein (2004) when he refers to 'meanings' as:

“... acquired by being born into and embedded in the social lifeworld, which include day to day interactions with the people around us".

Klein makes reference to work of Tsoukas (1996) and of Berger and Luckman (1967) in emphasizing subjectivity and reflexivity as key aspects of social scientific investigation. Tsoukas refers to subjectivity as consisting of a system of mental patterns acquired by individuals through past socialization and drawn upon in particular situations (i.e. sense-making). The so-called double hermeneutic of social research is immediately highlighted here. Only by explicit recognition of bias and reflexivity inherent in inquiries into this 'social lifeworld' can any general relevance of social research be established (Klein, 2004). In reflecting on meaning shaping, we can remind ourselves that the 'truth is the whole system' including both subject and object in relation to information: 
'A systemic notion of information would place it not just in the subject, or in the object, but in both of them and in what relates them.' (Callaos \& Callaos, 2002, p. 6)

The authors of this paper can see parallels here to the work of Habermas. Sometimes reflection on experienced reality is not a matter of choice. At times the world appears to kick back and force an individual to reflect. As Habermas points out, if an individual is experiencing an earthquake, she has no choice but to reconsider an assumption that the ground beneath her feet is solid (see for example discussion on p. 400 in Habermas, 1985).

Wittgenstein (1963) introduces what he calls "language games" as a metaphor for language use in the everyday course of practical life. He avoids giving a precise definition, but 'languaging' is nevertheless a rigorous aspect of his proposition. He expresses the problem as a need to reconcile a predictable structure that determines how words in language can be assembled, with a simultaneous need for use to be flexible. Any language structure must be dynamic to be able to account for regularities extending over time Language games, in Wittgenstein's terms, provide a vehicle for structure and flexibility to be achieved (for further discussion, see Nissen, 2007).

Human beings can be viewed as adaptive learning systems, and as such their behavior is not deterministic. Each human individual observes phenomena and interprets them from her own unique perspective (Bateson, 1972; Vickers, 1984). Human beings have free will to adapt their behavior to their perceptions in any feasible way. The greater the experienced complexity of the problem situation, the greater is likely to be the uncertainty experienced by the individuals. In the context of a complex problem space therefore it is likely that behavior patterns of different individuals will vary widely. The authors wish to emphasize their belief that a key aspect of discourse regarding critically informed contextual inquiry is an explicit recognition of individual uniqueness. When individual behavior is considered in the context of informing systems, as part of research discourse, it can be suggested that reductionist analysis ignores the possible extent of emergent properties. While researchers drawing upon a systemic ontology recognize emergent properties of a system, they may not always relate these to roles and perspectives of individual actors. An individual, acting in the context of an informing system, may generate emergent properties greater than those of the system as a whole (Bednar, 2001). This may arise when considering the influence of other systems of which she is a component. As has been pointed out elsewhere, any observation can only be made from the point of view of a particular observer (Maturana \& Varela, 1980) and consequently perception of a system varies with the stance of the observer (see e.g. Ulrich, 2001). Informing systems incorporate people engaged with meaning creation as part of their knowing. (NB Here, we refer to 'knowing' as experience, as opposed to 'knowledge').

Processes through which people create and recreate their knowing are at once deeply personal, contextual and social. Therefore knowing is susceptible to personal, contextual, and social biases. Gregory Bateson has suggested that knowing comes about through perception of change, i.e. of a 'difference that makes a difference' (Bateson, 1972). According to Weick (1995), knowledge creation takes place more readily through individual and collective sense-making activities within the cultural context of an organization. Such activities have been described as a negotiation of differing perspectives held by individuals - what Checkland calls 'Weltanschauungen' (Checkland, 1999). We (the authors of this paper) recognize that individuals can always select from a range of alternative viewpoints that may be contradictory, complementary or simply different, and that may overlap at any point.

Organizations have no embodiment beyond that of individuals, interacting within social communicational networks. 'Knowing' within an organizational context is formed by on-going construction of meanings by individuals, as they encounter new experiences and synthesize new data with existing 'knowledge' from past experiences (Langefors, 1966). In order to express their knowing 
in a process of creative development, individuals need space to explore their own understandings, since knowing may be deeply embedded and inaccessible to them. Nonaka and Konno (1998) described this space using the label 'originating $B a$ ' - that space where individuals share feelings, emotions, experiences and mental models.

Knowledge sharing is a form of communicative action which goes beyond a transmission of messages. Like 'knowing', it is subject to human sense-making and is susceptible to personal, contextual, and social biases. 'Knowing' may be constructed through teamwork in which individuals make a collaborative exploration of a problem-space. In his later work on organizational information systems, Claudio Ciborra discussed such exploration. Realizing that the openness and the dynamics of problem spaces create a multi-dimensional complexity, he turned to Heidegger for inspiration (Depaoli, 2006). Ciborra highlights a phenomenon that human beings cannot 'design' their own future. Ciborra suggests that, when confronted with a problem space they experience as complex, people turn first to existing knowledge, seeking for a solution within familiar competences and gradually 'tinkering' and moving outwards from this base (Ciborra, 1992). Only if such a strategy proves insufficient to deal with the problem might a person then turn to wider sources of unfamiliar knowledge. Ciborra highlights two types of evidence we encounter when approaching organizational phenomena: formal ideas or models derived from organization theories; and evidence belonging to a space in which informal expression can surface, which 'host the unexpected aspects of organizational life' (Ciborra, 2002, pp. 175-177). Such a space, he suggests, no model or theory could address. If researchers focus only on the first category of evidence, to the exclusion of the second, they miss the opportunity to encourage underlying phenomena to become 'unveiled' (Ciborra, 2002, p.178).

In practice, there may be constraints on the conditions within which effective team communication takes place, e.g. perceptions of differences in competence, culture, power or status among a group, which distort communicative processes. Habermas (1985) attempted to specify an 'ideal' situation for effective dialogue where conditions of equality of status, information and skill in discourse subsist between participants. Such conditions appear in the authors' experience to be a rare in everyday life. We consider it vital, therefore, that for the purpose to develop informing systems, vehicles are found to support individual and group sense-making activities.

In this section, we have discussed one instance of human activity where an intention is to inform but the result is misinforming, i.e. a paradox of 'objectivity'. Next we examine a case in which bivalued logic operates as a constraint upon informing processes.

\section{The Tyranny of 'Truth'}

In this section, we elaborate upon a second instance where the intention to inform fails. Here failure due to misguided use of bi-valued logic where para-consistent and multi-valued logic would have been more suitable (see Recher, 1969 for an extended description of multi-valued logic). This issue relates to the recognition of uncertainty, and contextual dependency, inherent in life as it is experienced. We, as human beings, do not always know the answer 'yes' or 'no' but are often constrained to act as if we did - i.e. to misinform.

The authors of this paper suggest that it is our common experience in everyday life that, when posing a question to someone, we might receive the answer 'it depends'. Here, an individual gives an answer conditional on obtaining further data about the context of the question. We infer from this that people might be comfortable with multi-valued logic when dealing with everyday problems (i.e. things are not necessarily assessed on a scale of 'truth' or 'falsity'). Clearly, when Ulrich (2001) discusses the need for boundary critique in systemic inquiry, he is giving recognition to this phenomenon of 'it depends'. Observation, for Ulrich, is critically dependent upon the stance of the observer. This links directly to the argument put forward by Maturana and Varela 
(1980), pointing out that no observations are independent of particular people who observe. Vickers (1984) adds to this focus in highlighting human interpretive processes as incorporating 'appreciative settings' reflecting an individual's previous life experiences. Similar views are expressed by Langefors (1966) in setting out his Infological Equation. We can also refer to work by Bateson (1972), in which he points out the contextually dependent nature of human learning, and hence understanding of any phenomenon. If human learning is by nature contextually dependent, then there is no reason to approach more complex problems with an assumption that it is necessary to break them down systematically or to apply bi-valued logic. Whilst there may be occasions when it is beneficial to break problems down and simplify them, this need not be done as a matter of cause. In our view an approach involving routine and systematic attempts to simplify inquiry is reductionist. Attempting to identify every aspect of a problem situation separately, in isolation from its context, in order to establish the 'truth' or 'falsity' of certain key parameters ignores emergence. Instead, we would advocate 'complexification' of inquiry, creating a multivalued assessment and categorization through elaboration upon individual expression of 'it depends'. The authors see emphasis on use of bi-valued logic as restrictive of individual choice. In everyday life, human beings are confronted with the need to make choices. It is important to examine the element of choice and judgment available to individuals. Often, the variety of choice open to individual people is much wider than is commonly expected (Gilovich, 1991). The categorization, as presented in Figure 5, outlines a phenomenon, i.e. that decision makers are able to keep in mind that they are asserting beliefs of truths rather than truths - exercising judgment (Bednar at al, 2006).

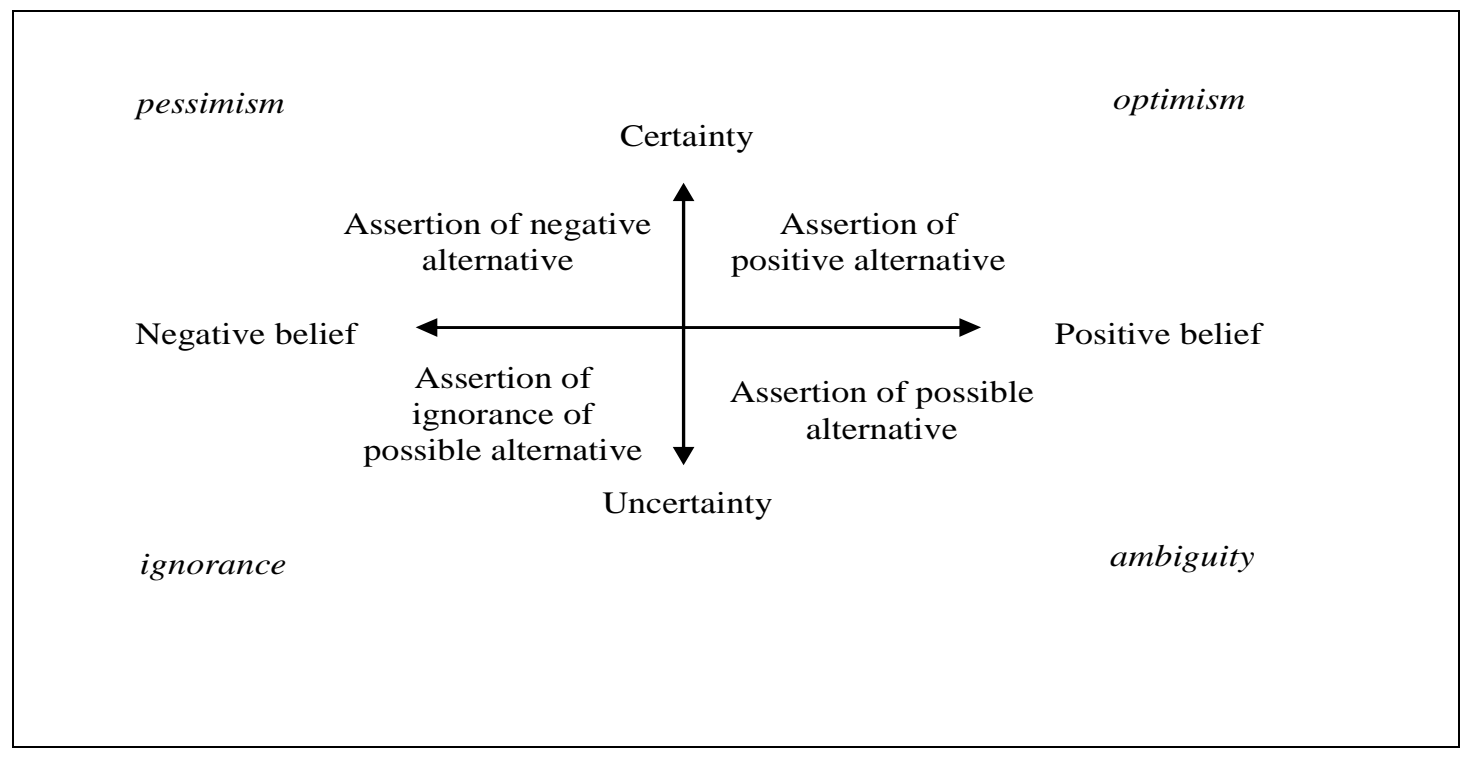

Figure 5: Categories of assertions of belief.

All four alternatives can be seen to be variants of the answer 'it depends', the main difference lies in character and degree of the espoused certainty (see example in Table 3, from Bednar et al, 2006). The logic also implies that choices need to be made for each individual alternative. Any assertions made, even if assumed to be generally valid, are not obviously valid under all conditions and out of context. Each assertion requires a decision. Each decision is chosen as a result of an assessment of risk of being 'wrong' where the fit between assumptions of context and generalization is taken into consideration. This phenomenon is a result of a strategy for dealing with uncertainty in context. It. happens as an aspect of negotiation, when people (analysts) try to make 
sense of their own, and each other's, narratives regarding their understandings and definitions of a problem space.

It should be noted that a further dimension, commitment (i.e. strength of conviction), is not reflected in the model in Figure 5. Figure 6 reflects four different values within the world of certainty. The four quadrants illustrate that participants may be committed to different types of belief. It is possible for instance to be certain that you have not enough information to make a decision, or certain that there is a paradoxical situation in which apparent alternatives are both true or both untrue. This (relation to level of commitment as described in Figure 6) is not the same as experiencing uncertainty in relation to a question were the values of particular conditions cannot be ascertained (see Figure 5).

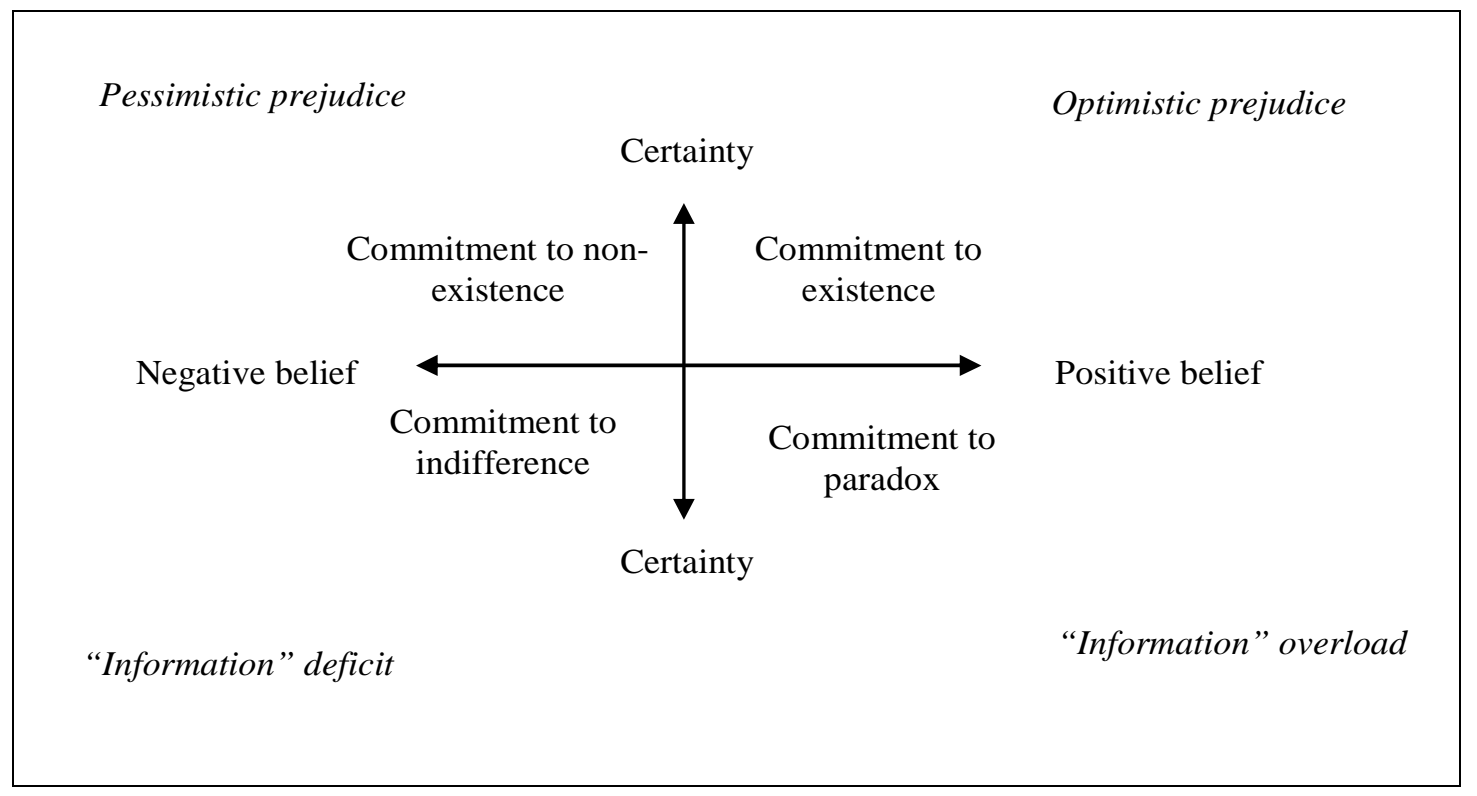

Figure 6: Categories of Commitment.

In everyday life, we are skilled in ignoring limitations in bi-valued logic because our familiarity with the context of a problem space enables us to compensate selectively. However, this habitual approach could easily become skilled incompetence (Argyris, 1990) when a problem space is complex and difficult to comprehend. This habitual oversimplification can be a problem since it can lead to ignorance of the range of possible alternatives (Gilovich, 1991), through complacency. Although this may hold true most of the time, bi-valued logic has received considerably more credit than its real value merits, and has entered realms 'incompatible' with its nature.

The authors believe that a focus on bi-valued logic would constrain normal exercise of human judgment, since people are capable of using multi-valued logic in a process of creating assertions. In recognizing that human reasoning supports contradictions in forming judgments, we perceive a need for any supportive system we create to extend beyond bi-valued logic.

A desire to avoid information overload, and to navigate through rich and diverse sources of potential meaning can lead individuals to prefer methodologies which purport to simplify a problem space. Such a reductionism, while useful in many cases, tends not to handle complexity in contextual problems very well. We suggest that it is preferable to confront the complexities and "mud- 
dle' presented by organizational life by undertaking structured, but systemic inquiry into contextual dependencies (see also Bednar, 2000 for an example of a framework which support such an undertaking). In particular, we believe it is vital to maintain a focus on unique, individual beliefs and perspectives within the context of collective exploration of problem spaces. In cybernetics, it is recognized that every distinct dimension of a complex system needs to be controlled in a way which is appropriate to its characteristics. This is known as Ashby's law of requisite variety (Ashby, 1964). Similarly, we believe, when conducting inquiry, the multitude of dimensions of a complex problem space requires appropriate analytical approaches.

Table 3: Example of multi-valued reasoning

Let us assume that you and I are in Portsmouth, on the south coast of England.

Assertion of positive alternative:

If you asked me 'Is it possible to get to Southampton this afternoon?' I would answer 'Yes, I believe so. It is twenty miles by road or rail, and there are plenty of services.'

Assertion of negative alternative:

If you asked me 'Is it possible to get to Buenos Aires this afternoon?' I would answer 'No, I doubt it. Even if there was a flight from the local airport today, the distance is so great that you would not arrive until tomorrow.'

Assertion of possible alternative:

If you asked me 'Can I get to Paris this afternoon?' I would answer 'I expect so. It could be pos-sible if there is an afternoon flight from the local airport. Assuming seats are available and you can afford the fare, then perhaps you can'.

Assertion of ignorance of possible alternative:

If you asked me 'Can I get to Timbuktu this afternoon?' I would say 'I have no idea. I am not sure where it is or even which continent it is in. I do not know whether there are services from Portsmouth or even direct flights from the UK'.

In this section, we have discussed how human reasoning is based in multi-valued, rather than bivalued logic. We discuss how this relates to the uncertainties and contextual dependencies inherent in human experience of life as it is lived,and the consequences for informing processes when people fail to recognize this. We emphasize that where people resort to reductionism, this should be selective rather than habitual and requires critical reflection. It should also be accompanied by selective 'complexification'.

\section{Conclusions}

In informing science, the focus is on efforts made by people to provide their clients with 'information' in a form, format and schedule that maximizes its effectiveness. Depending upon ones relationship to the concept of bias what is meant by 'providing information' and 'effectiveness' will be significantly different. From Logical Empiricist perspective, mainly denotational features of language become influential, while from a Hermeneutic Dialectic perspective, mainly connotational features are more significant. This includes strategies adopted in efforts to inform. For instance, from a Logical Empiricist perspective, messages by which data are transmitted may also contain meaning which needs only to be decoded by a receiver in order for that person to become informed. This creates a focus upon technical issues concerned with coding, decoding and transmission of a message. However, from a perspective of Hermeneutic Dialectics, meaning is cre- 
ated by those individuals who are seeking to orient or be oriented within a particular context to which a message may be relevant. Here, therefore, a technical focus would be inadequate to inquire into processes of informing. The focus must also incorporate individual human sensemaking. As indicated by Nissen (2002), drawing on Apel (1980) and Radnitzky (1973), these two research traditions should be regarded as supplementary. In the context of inquiry into human spheres of action, neither alone can be sufficient.

We do not suggest that there is no value in researchers setting out with a desire to achieve objectivity in their inquiries. However, we do believe that objectivity is in practice elusive and that it is necessary to recognize this in any endeavour. When use of language is recognized to be connotative, then communication is about efforts to orient someone within her cognitive domain. It is the orientee who creates meaning by delving into her cognitive domain in order to reduce uncertainty. Hence, she draws upon prior consensual linguistic experiences. The denotative function of language presupposes much prior mutual interaction and learning between members of informing systems. We have attempted to highlight examples of concerns within both professional and academic communities of practice, relating to experienced breakdowns in communication, i.e. misinforming. We have attempted to put these issues into a context of critical systemic thinking. We have also made efforts to describe approaches intended to support people in their efforts to cope with these experiences.

In this paper, we have included two specific examples of situations in which those taking part in inquiry, or making efforts to communicate, may intend to take a neutral or objective stance, and yet nevertheless find themselves entrapped in processes of misinforming. These examples relate to human reasoning (imposing a scale of bi-valued logic on multi-valued reasoning); and human perspective (making attempts to create a position of objectivity) in denial of bias that participants bring to any informing process.

\section{References}

Apel, K-O. (1980). Towards a transformation of philosophy. G. Adey \& D. Frisby, Translators. London: Routledge and Kegan Paul. Original work published in 1973

Argyris, C. (1990). Overcoming organizational defenses: facilitating organizational learning. Prentice Hall: New Jersey

Ashby, R. (1964). An introduction to cybernetics. London: Methuen.

Avison, D., \& Fitzgerald, G. (2002). Information systems development: Methodologies, techniques and tools (4th ed.). London: Mc-Graw Hill.

Baer, T. (2007a). So many paths to Nirvana. The Register. Retrieved April 8, 2008, from http://www.regdeveloper.co.uk/2007/11/28/automating application_lifecycle/

Baer, T. (2007b). The great BPM land grab. OnStrategies Perspectives. Retrieved April 8, 2008, from http://www.onstrategies.com/blog/?p=233

Bateson, G. (1972). Steps to an ecology of mind. Chicago: University of Chicago Press.

Bednar, P. M. (2000). A contextual integration of individual and organisational learning perspectives as part of IS analysis'. Informing Science: the International Journal of an Emerging Transdiscipline, 3(3), 145-156. Retrieved February 2, 2008, from http://inform.nu/Articles/Vol3/v3n3p145-156.pdf

Bednar, P. M. (2001). Individual emergence in contextual analysis. Problems of individual emergence. Proceedings of 12th Biannual 'Problems of...' Systems Conference, Amsterdam, April 16-20. 
Bednar, P.M., Welch, C., \& Katos, V. (2006). Four valued logic: Supporting complexity in knowledge sharing processes. Proceedings of 7 th European Conference on Knowledge Management, Corvinus University, Budapest, Hungary, September.

Berger, P. L., \& Luckmann, T. (1967). The social construction of reality: A treatise in the sociology of knowledge. Garden City, NY: Anchor Books.

Bohm, D. (1992). Thought as a system. Routledge.

Callaos, N., \& Callaos, B. (2002). Toward a systemic notion of information: Practical consequences. Informing Science: The International Journal of an Emerging Transdiscipline, 5(1), 1-11. Retrieved April 8, 2008, from http://inform.nu/Articles/Vol5/v5n1p001-011.pdf

Checkland, P. (1999). Systems thinking, systems practice: A 30-year retrospective. Wiley.

Ciborra, C. U. (1992). From thinking to tinkering: The grassroots of strategic information systems. Information Society, 8, 297-309.

Ciborra, C. U. (2002). The labyrinths of information: Challenging the wisdom of systems. Oxford: Oxford University Press.

Cohen, E. (1999). Reconceptualising information systems as a field of the transdiscipline informing science: From ugly duckling to swan. Journal of Computing and Information Technology, 7(3), 213-219.

Cohen, E. (2005). Call for chapters: Bias, misinformation and disinformation in informing systems. Email from list@informingscience.org

Depaoli, P. (2006). The influence of Martin Heidegger on Claudio Ciborra's writings. In Information systems and people: Implementing information technology in the workplace, Proceedings of 3rd itAIS Conference, 26-27 October 2006, Università Bocconi, Milan, Italy.

Fiske, J. (1982). Introduction to communication studies. London: Routledge.

Gilovich, T. (1991). How we know what isn't so: The fallibility of human reason in everyday life. New York: The Free Press.

Habermas, J. (1985). Lifeworld and System: A Critique of Functionalist Reason (3rd ed.), Vol 2 of The Theory of Communicative Action (T. McCarthy, Translator.). Boston: Beacon Press.

Haines L (2007). Canadian runs up $\$ 85,000$ mobe bill. Unlimited browser plan? Not exactly... The Register. Retrieved April 8, 2008 from http://www.theregister.co.uk/2007/12/13/mobe_bill/

Hay, N. (2007). Towards a visualisation of key concepts relating to the etiology, effect and therapy of paradoxical communication within relationships which are or have become abusive - Creation of a self-aid Website. Systemica, Journal of the Dutch Systems Society, Vol. 14: Problems of Individual Emergence, 167-180.

Heidegger, M. (1962). Being and time. Oxford Blackwell.

Klein, H. K. (2004). Seeking the new and the critical in critical realism: déjà vu? Information and Organization, 14, 123-144.

Knox, K. T. (2007). The various and conflicting notions of information. Issues in Informing Science and Information Technology, 4, 676-689. Retrieved April 8, 2008 from http://proceedings.informingscience.org/InSITE2007/IISITv4p675-689Knox452.pdf

Langefors, B. (1966), Theoretical analysis of information systems. Lund: Studentlitteratur.

Langefors, B. (1995). Essays on infology - Summing up and planning for the future. Lund: Studentlitteratur.

Lasswell, H. D. (1948). The structure and function of communication in society. In L. Bryson (Ed.), The Communication of Ideas. New York: Institute for Religious and Social Studies, Jewish Theological Seminary of America. 
Maqsood, T., Finegan, A. D., \& Walker, D. H. T. (2004). Biases and heuristics in judgment and decision making: The dark side of tacit knowledge. Issues in Informing Science and Information Technology, 1 , 295-301. Retrieved April 8, 2008, from http://articles.iisit.org/050maqso.pdf

Maturana, H. R., \& Varela, F. J. (1980). Autopoiesis and cognition: The realization of the living. Dordrecht: D. Reidel Publishing Company.

Mumford, E. (2003). Redesigning human systems. London: IRM Press.

Nissen, H-E. (1989). Information systems development for responsible human action. In Systems development for human progress. Proceedings of the IFIP 8.21989 working conference. Amsterdam: NorthHolland publishers.

Nissen, H-E. (2002). Challenging traditions of inquiry in software practice. In Y. Dittrich, C. Floyd, \& R. Klischewski (Eds.), Social thinking - software practice (pp 69-90). Cambridge Mass: MIT Press.

Nissen, H-E. (2007). Using double helix relationships to understand and change informing systems. In H-E. Nissen, P. M. Bednar, \& C. Welch (Eds.), Use and design in IS: Double helix relationships? Monograph in Informing Science: The International Journal of an Emerging Transdiscipline, 10, 21-62. Retrieved April 8, 2008, from http://inform.nu/Articles/Vol10/DblHelix021-062.pdf

Nissen, H-E., Bednar, P. M., \& Welch, C. (Eds.). (2007). Double helix relationships in use and design of informing systems: Lessons to learn from phenomenology and hermeneutics [Editorial]. In H-E. Nissen, P. M. Bednar, \& C. Welch (Eds.), Use and design in IS: Double helix relationships? Monograph in Informing Science: The International Journal of an Emerging Transdiscipline, 10, 1-19. Retrieved April 8, 2008, from http://inform.nu/Articles/Vol10/DblHelix001-019.pdf

Nonaka, I. \& Konno. (1998), The concept of 'Ba': Building a foundation for knowledge creation. California Management Review, 40(3), 40-54.

Oxford English Dictionary (2nd ed.). (1989). C. Soanes \& A. Stevenson (Eds.). Oxford University Press

Radnitzky, G. (1973). Contemporary schools of metascience (3rd, enlarged edition.). Chicago: Humanities Press / Henry Regnery Company.

Recher, N (1969), Many-valued logic, McGraw Hill, New York

Richards, I. A. (1968). So much nearer: Essays toward a world English (2nd ed). New York: Harcourt, Brace \& World.

Rosenberg, D., \& Stephens, M. (2007). Use case driven object modeling with UML? Theory and practice. APRESS ACADEMIC.

Salvage, I., \& Dhanda, I. S. (2007, September). IT service management: Is it now too important to leave to the IT department alone? How and why the IT function needs to change its relationship with the business. [IBM White Paper.] IBM Global Technology Services. Retrieved 11 November 2007 from http://whitepapers.theregister.co.uk/search/?q=IBM

Saussure, F. de (1974). Course in general linguistics. (J. Cullen, Ed. and W. Baskin, Trans.). London: Fontana.

Shannon, C. F., \& Weaver, W. (1949). A mathematical model of communication. Urbana, IL: University of Illinois Press.

Schutz, A. (1967). Phenomenology of the social world. Northwestern University Press.

Sommerville, I. (2007). Software engineering 8, (8th ed.). Harlow: Pearson Education.

Stephens, M. (2007a). Why UML won't save your project. The Register. Retrieved November 11, 2007 from http://www.regdeveloper.co.uk/2007/10/08/uml_not_magic_bullet/

Stephens, M. (2007b). The ICONIX process in pieces: Domain modelling. The Register. Retrieved November 13, 2008 from http://www.regdeveloper.co.uk/2007/11/13/domain_modelling_excerpt/ 
Stowell, F., \& West, D. (1994). Client-led design: A systemic approach to information systems definition. London: McGraw-Hill.

Tsoukas, H. (1996). The firm as a distributed knowledge system: A constructionist approach.. Strategic Management Journal, 17, 11-25 (Winter Special Issue).

Ulrich, W. (1994). Critical heuristics of social planning: A new approach to practical philosophy (2nd ed.). New York and London: John Wiley \& Sons.

Ulrich, W. (2001). Critically systemic discourse: A discursive approach to reflective practice in ISD. Parts 1 \& 2. Journal of Information Technology Theory and Application (JITTA), 3(3), 55-106.

Vance, A. (2007). Microsoft surprises itself with six-month late Hyper-V beta. Easy to impress. The Register. Retrieved February 2, 2008, from http://www.theregister.co.uk/2007/12/14/beta_hyperv_microsoft/

Vickers, G. (1984). Human systems are different. London: Harper \& Row.

Wagner, H. (Ed.). (1970). Alfred Schutz on phenomenology and social relations: Selected readings. Chicago: University of Chicago Press.

Weick, K. (1995). Sensemaking in organizations. Thousand Oaks: Sage Publications.

Whitaker, R. (2007). Applying phenomenology and hermeneutics in IS design: A report on field experiences. In H-E. Nissen, P. M. Bednar, \& C. Welch (Eds.), Use and design in IS: Double helix relationships? Monograph in Informing Science: The International Journal of an Emerging Transdiscipline, 10, 63-96. Retrieved February 6, 2008, from http://inform.nu/Articles/Vol10/DblHelix063-096.pdf

Wittgenstein, L. (1963). Philosophical investigations. Oxford: Basil Blackwell.

\section{Biographies}

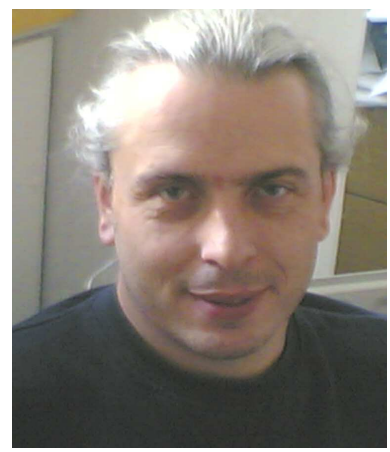

Peter M Bednar is an Engineer and Senior Lecturer. His research covers contextual analysis, organizational change and information systems development, and he has published several book chapters and many articles in these fields. He is a member of the Information Systems group in the School of Computing at the University of Portsmouth, UK and is also affiliated to the Department of Informatics at Lund University, Sweden.

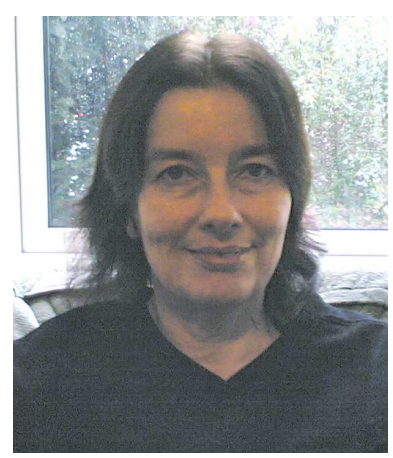

Christine Welch is a Principal Lecturer in the Department of Strategy and Business Systems, part of the Business School at the University of Portsmouth, UK. Her research interests include critical systemic thinking, contextual analysis and organizational change, and she has published several book chapters and articles in these fields. She is convener of the Southern Regional Centre of the UK Systems Society. 